\title{
A INCORPORAÇÃO DE DIREITOS E GARANTIAS INDIVIDUAIS: UMA ANÁLISE DA ASSEMBLEIA NACIONAL CONSTITUINTE À LUZ DO DIREITO INTERNACIONAL DOS DIREITOS HUMANOS
}

\author{
Sofia Sewnarine Negrão* \\ Cristina Figueiredo Terezo Ribeiro*
}

Resumo: O presente artigo possui o objetivo de analisar a influência das normas oriundas dos Sistemas Internacionais de Proteção dos Direitos Humanos para a formulação do Capítulo dos Direitos e Garantias Individuais do texto constitucional de 1988. Foram analisadas as Atas da Assembleia Nacional Constituinte (ANC), escolhendo subcomissões que ensejaram a escrita do Capítulo I do texto constitucional. Na construção do artigo, observam-se quais dispositivos (que não foram alterados por emenda) são semelhantes aos textos de normas internacionais e obtiveram influência direta dos referidos diplomas internacionais.

Palavras-chave: Assembleia Nacional Constituinte; História Constitucional; Direito Internacional dos Direitos Humanos; Tratados de Direitos Humanos; Direitos e Garantias Individuais

\section{THE INCORPORATION OF INDIVIDUAL GUARANTEES AND RIGHTS: AN ANAL YSIS OF THE NATIONAL CONSTITUTIONAL ASSEMBLY PURSUANT TO THE INTERNATIONAL HUMAN RIGHTS LAW}

\begin{abstract}
This article aims to analyze the influence of the guidelines from the International Human Rights Protection Systems in the development of the Chapter of Individual Rights and Guarantees from the 1988's Constitution. The Acts of the National Constituent Assembly (NCA) were analyzed, choosing subcommittees that led to the writing of Chapter I of the Constitutional text. In the construction of the article, we identify which provisions (that were not altered by amendment) are similar to the texts of international guidelines and were directly influenced by the refered international documents.
\end{abstract}

Keywords: National Constituent Assembly (NCA); Constitutional History; International Human Rights Law; Human Rights Treaties; Individual Rights and Guarantees.

1. Introdução

Criado após as atrocidades dos crimes contra a humanidade cometidos no decorrer da Segunda Guerra Mundial, o Direito Internacional dos Direitos Humanos inaugura seu período

\footnotetext{
* sofiasew21@gmail.com, advogada, graduada em Direito pela Universidade Federal do Pará, Mestranda em Direito pela Universidade Federal do Pará, ex bolsista e voluntária da Clínica de Direitos Humanos da Amazônia. *cfterezo@hotmail.com, advogada, Doutora em Direito pela Universidade Federal do Pará, coordenadora da Clínica de Direitos Humanos da Amazônia da Universidade Federal do Pará, visiting scholar da American University, Washington College of Law.
} 
de interação entre os países após 1945, com a criação da Organização das Nações Unidas e a formulação da Declaração Universal dos Direitos Humanos (DUDH) em 1948, seguida de outros documentos importantes deste organismo internacional (CANÇADO TRINDADE, 2006). Apesar da ampla aceitação do documento pela comunidade internacional, sobretudo dos países que buscavam se reestruturar após grandes conflitos armados e permanentes violações de direitos humanos, o documento não era admitido como vinculante entre os países, bem como não era suscetível ao levantamento de reservas pelos Estados que almejavam fazer parte deste conjunto de normas, que se anunciavam.

Embora não fosse admitida como obrigatória a vinculação ao texto da $\operatorname{DUDH}^{1}$, a influência internacional existente sobre as normas de direitos humanos permitiu que inúmeros países aproximassem seus sistemas constitucionais e infraconstitucionais ao considerado internacionalmente. Após este período, e com a necessidade de afirmação de maior gama de direitos, foram criados pactos que versavam sobre direitos civis e políticos - Pacto Internacional sobre Direitos Civis e Políticos (1966) - a direitos econômicos, sociais e culturais - Pacto Internacional sobre Direitos Econômicos, Sociais e Culturais (1967) e, além destes, outros tratados também foram criados para prevenir e proibir de forma mais específica a violação de determinados direitos humanos e proteger grupos vulneráveis específicos (MUÑOZ, 2017) 2 .

Os países, que ratificavam estes tratados, deveriam determinar o status hierárquico interno das normas de Direito Internacional e possuíam a responsabilidade de incorporar e compatibilizar suas normas em acordo com a proteção conferida pelos tratados que assumiu, sob pena de constrangimento internacional. Alguns países que ainda não haviam ratificado estes instrumentos, também recebiam fortes influências para a integração de normas mais protetivas aos direitos humanos. Neste sentido, ainda que tais normas não obtivessem status hierárquico

\footnotetext{
${ }^{1}$ Alguns doutrinadores (André de Carvalho Ramos, Diego Rodriguez-Pinzón, Flávia Piovesan) entendem que as Declarações de Direitos Humanos, seja a Universal da ONU de 1948 ou a Americana, do mesmo ano, teriam força jurídica vinculante por serem utilizadas nos fundamentos das decisões de Tribunais Internacionais, como a Corte Internacional de Justiça e a Corte Interamericana de Direitos Humanos. Thomas Buergenthal e Louis B. Sohn entendem que a Declaração é um instrumento formal e solene, cujos princípios e normas teriam sido aprovados por Estados-membros por serem reconhecidamente parte do Direito Internacional costumeiro, sendo assim juridicamente vinculante. No entanto, a questão não é pacífica na doutrina, vez que as Declarações não dispõem de mecanismos de monitoramento, diferentemente dos Tratados, Convenções e Pactos, os quais preveem tais mecanismos, entendidos como convencionais.

${ }^{2}$ Convenção Contra a Tortura e Outros Tratamentos ou Penas Cruéis, Desumanos ou Degradantes (1984).
} 
no ordenamento interno destes países, influenciaram significativamente sua estruturação constitucional.

O Brasil, que perpassou por um conjunto de acontecimentos atinentes ao contexto latino americano, sobretudo de transição democrática, passou por um intenso movimento de constitucionalização, marcado pela junção de forças opositoras reunidas para a discussão sobre estruturação de um texto constitucional, produto do processo de evolução do constitucionalismo regional $^{3}$ e, que, em sua última etapa, objetivava solucionar as crises de direitos humanos surgidas na década de 70 (GARGARELLA, 2018).

Sob um processo específico de formulação da nova constituinte, após a ditadura militar fundado em 1964, a Constituição da República Federativa do Brasil de 1988 sofreu diversas influências, que variavam desde a intensa participação de movimentos sociais em audiências públicas, no esforço de incorporação de seus interesses (VIEIRA, 2018) e, até mesmo as normas de Direito Internacional, que estavam em viés de estruturação doméstica nos países. Este momento foi marcado por um processo de confluência de forças políticas de diversos setores, que, por vezes, tensionava com os direitos e garantias individuais estruturados internacionalmente.

Embora o artigo $5^{\circ}$ da Constituição Federal, que rege por completo o Capítulo concernente os Direitos e Deveres Individuais e Coletivos, possua uma ampla gama de diretos positivados que garante direitos específicos, seu texto constitucional aproxima-se de maneira sensível a determinados textos de tratados internacionais, ainda que, no momento de sua criação alguns tratados ainda estivessem apenas em plano de assinatura, mas não com vigência e outros, tampouco estavam em plano de negociação.

$\mathrm{Na}$ Constituição, o status das normas de direitos humanos consagradas internacionalmente foi aspecto considerado controvertido, por não haver menção expressa nos primeiros anos após a promulgação do documento, coube ao Supremo Tribunal Federal (STF) interpretar qual seria a condição hierárquica destas normas, quando ratificadas pelo Brasil. Nesse sentido, o STF, após modificações em seu entendimento, passou a decidir pela supralegalidade dos tratados e, esta interpretação, após a Emenda ${ }^{\circ}$ 45/2004, passou a coexistir com o status constitucional das normas que passavam pela aprovação de um quórum específico nas duas casas do Congresso Nacional, de maneira que as demais normas que não foram

\footnotetext{
${ }^{3}$ La evolución del constitucionalismo regional podría ser dividida en cuatro etapas, dirigidas: i) el
} 
constitucionalismo "experimental", particularmente preocupado por la consolidación de la independencia (1810$1850)$; ii) el "fundacional", interesado, sobre todo, en la consolidación económica (1850-1917); iii) el "social", orientado a recuperar la olvidada "cuestión social" (1917-1980) y; iv) el de los derechos humanos, dirigido a sanear la crisis de derechos humanos propia de la década del 1970 (1980-2000) (GARGARELLA, 2018).

aprovadas por meio deste procedimento, continuariam sob categoria inferior ao texto constitucional.

Com efeito, faz-se necessário analisar o momento da construção e estruturação da Constituição brasileira de 1988, para compreender a questão do seguinte problema: quais as influências das normas internacionais, oriundas do Direito Internacional dos Direitos Humanos, para a formulação dos direitos e garantias individuais presentes no artigo $5^{\circ}$ da Constituição brasileira?

Para responder a esta pergunta, foram eleitas as Atas da Assembleia Nacional Constituinte (ANC) como objeto de estudo, escolhendo subcomissões específicas que ensejaram a escrita do Capítulo I do texto Constitucional. A fim de construir o escopo do presente artigo, primeiramente, observam-se como objetivos específicos, compreender quais dispositivos (que não foram alterados por emenda) são semelhantes aos textos de Convenções, Tratados e Declarações Internacionais e, após esta verificação, analisar dentre os artigos definidos anteriormente, quais obtiveram influência direta dos referidos diplomas internacionais.

Em pesquisa preliminar nas principais plataformas de dados, bem como revistas e repositórios, poucas pesquisas foram encontradas que trataram especificamente do conjunto de direitos e garantias individuais inseridos na Constituição e, destas, um número menor ainda obtinha como objeto a análise das Atas da Assembleia, das quais os principais trabalhos tratavam sobre democracia, processo de redemocratização e segurança nacional. Não foram encontrados estudos que relacionavam de forma específica os direitos contidos no art. $5^{\circ}$ da Constituição e as normas de Direito Internacional de Direitos Humanos.

O alcance destas análises será realizado por meio de uma abordagem indutiva, que parte de questões e verificações específicas, para que então seja possível generalizar as constatações (GIL, 2019). Para isso, a pesquisa empírica em nível exploratório será realizada por meio da revisão documental em análise qualitativa, com o intuito de possibilitar a utilização de métodos construídos e estáveis (QUIVY; CAMPENHOUDT, 1992). A técnica de pesquisa utilizada será a técnica de análise de conteúdo (GIL, 2019), a fim de sistematizar os documentos e realizar inferências. 
2. O processo histórico constitucional do Brasil e a organização da Assembleia Nacional Constituinte

A Constituição da República Federativa do Brasil, promulgada em 1988, ensejou uma movimentação social e política jamais vista no cenário constitucional brasileiro (VIEIRA, 2018). Desde os momentos prévios à formação da Comissão Constituinte, que envolviam a transição de governo e a possibilidade de convocação da assembleia para a formulação de um novo texto constitucional, bem como a necessidade de reafirmar, por meio de um mecanismo estruturante, a existência de um regime de governo democrático no Brasil, mobilizaram diversas camadas populacionais (BARBOSA, 2012).

O processo de ruptura com o regime autoritário emergente foi evidenciado por um período de redemocratização e as manifestações populares envolvendo a liberdade de voto. As “diretas já", ainda que não tivessem alcançado o objetivo final de garantir o voto direto dos eleitores brasileiros (BARBOSA, 2012), foram responsáveis pela movimentação e estímulo popular para a criação de uma nova estrutura constitucional e, por conseguinte, um novo texto que representasse mudanças institucionais e garantisse o exercício democrático.

A independência congressista e a assunção do poder por um presidente civil (Tancredo Neves - que em seus discursos de manifestava a favor de uma nova Constituição), sustentadas pela ideia de formulação de uma Assembleia Nacional Constituinte (ANC), impulsionaram ainda mais a população para reivindicar o processo de mudança do regime que ainda guardava grandes resquícios, tendo em vista que alguns aportes legislativos utilizados nos governos militares, ainda permaneciam (BARBOSA, 2012).

Com efeito, uma das missões unânimes foi a estruturação de dispositivos que simbolizavam a ruptura com o sistema vigente anteriormente (VIEIRA, 2018), bem como a adição de seguros constitucionais para que determinados crimes cometidos no passado - a exemplo das transgressões, torturas e outras penas e tratamentos cruéis e degradantes - não voltassem a ocorrer. Se de um lado, se sistematizava-se profunda rejeição aos crimes cometidos durante a ditadura, a concretização de direitos fundamentais, antes modificados por meio dos atos institucionais e restringidos de forma arbitrária, apresentava-se como a funcionalidade da constituinte em viés de construção.

José Sarney, que assumiu a presidência após a morte abrupta de Tancredo Neves, foi o responsável, apesar de algumas resistências (constituintes apartados), pela Emenda 
Constitucional $\mathrm{n}^{\circ} 26$ de novembro de 1985, que convocava uma nova constituinte; logo, os possíveis moldes para uma nova carta constitucional começam a surgir em espaço concreto. Neste momento, os deputados e senadores que pertenceriam ao Congresso Nacional, também seriam legisladores ordinários da Constituição, de maneira que a Assembleia Nacional Constituinte, presidida por Ulysses Guimarães, contou com a presença de 487 Deputados e 72 Senadores (BARBOSA, 2012).

A Constituinte de 1988 foi planejada e promulgada após a publicação de diversos textos que versavam sobre o Direito Internacional dos Direitos Humanos, tais como a Declaração Universal dos Direitos Humanos (DUDH) (1948), a Convenção Americana de Direitos Humanos (CADH) (1969), a Convenção sobre Eliminação de Todas as Formas de Discriminação Racial (1966), a Convenção sobre Eliminação de Todas as Formas de Discriminação contra a Mulher (1979), a Convenção das Nações Unidas contra a Tortura (1984), que apesar de ainda não ratificados pelo Estado brasileiro, já exerciam influência direta sobre os debates internos relacionados à inserção de direitos na Constituição.

No processo constituinte brasileiro, as normas internacionais de proteção aos direitos humanos ainda não contavam com hierarquia determinante, que apesar de ser debatida e levantada a necessidade de consonância com os dispositivos constitucionais (BRASIL, 1987) ${ }^{4}$, foi determinada a abertura constitucional aos tratados, sem, entretanto, especificar seu status normativo. Por esta razão, somente após a Emenda Constitucional n 45/2004, as normas de tratados internacionais, que passassem pelo quórum específico nas duas Casas do Congresso Nacional, obteriam o status de norma constitucional, integrando assim o conjunto de normas hierarquicamente superior do ordenamento jurídico e sobre aquelas que não fossem submetidas ou aprovadas por este procedimento, coube ao Supremo Tribunal Federal enquadrar o texto ao status de supralegalidade ${ }^{5}$.

Ainda que consagradas estas delimitações estruturais, a única Convenção que possui status de norma Constitucional ratificada pelo Brasil, é a Convenção Internacional sobre os Direitos das Pessoas com Deficiência e seu Protocolo Facultativo, assinados em Nova York, em 30 de março de $2007^{6}$. As demais normas possuem o status conferido pelo STF.

Cançado Trindade (2006) conclui a necessidade de existência de um núcleo mínimo inserido no texto constitucional, referente às normas de direitos humanos aceitáveis internacionalmente. Além de assinalar sobre a necessidade de interação entre o direito 


\title{
A INCORPORAÇÃO DE DIREITOS E GARANTIAS INDIVIDUAIS: UMA ANÁLISE DA ASSEMBLEIA NACIONAL CONSTITUINTE À LUZ DO DIREITO INTERNACIONAL DOS DIREITOS HUMANOS
}

\begin{abstract}
${ }^{4}$ Art. $5^{\circ}[\ldots] \S 3^{\circ}$ Os tratados e convenções internacionais sobre direitos humanos que forem aprovados, em cada Casa do Congresso Nacional, em dois turnos, por três quintos dos votos dos respectivos membros, serão equivalentes às emendas constitucionais (BRASIL, 1988).

${ }^{5}$ A tese da supralegalidade foi questão estruturada e adotada pelo Supremo Tribunal Federal no decorrer do tempo, primeiramente como norma legal, resolvida pelo critério da Lei mais moderna RE 80.004/SE, mantendo este entendimento em 1995 por meio do HC 72.131/RJ (1995), após estes momentos, foi fundada a tese através de voto obter dictum do RHC 79.785/RJ (2000) e reafirmada em RE 464.343/SP (MAUÉS; MAGALHÃES, 2016).

${ }^{6}$ Decreto ${ }^{\circ}$ 6. 949 de 25 de agosto de 2009. [...] Considerando que o Congresso Nacional aprovou, por meio do Decreto Legislativo no 186, de 9 de julho de 2008, conforme o procedimento do $\S 3^{\circ}$ do art. $5^{\circ}$ da Constituição, a Convenção sobre os Direitos das Pessoas com Deficiência e seu Protocolo Facultativo, assinados em Nova York, em 30 de março de 2007 (BRASIL, 2009).
\end{abstract}

doméstico e os tratados internacionais sobre direitos humanos, bem como compreender a necessidade dos Estados assumirem compromissos para a efetivação de direitos e garantias individuais.

A mobilização pela assunção de compromissos internacionais deve refletir a necessidade de firmar bases para a proteção de direitos e a não repetição das arbitrariedades ocorridas durante a ditadura militar. A compatibilização do texto constitucional promoveria maior força hierárquica aos direitos humanos e, assim, maior abrangência protetiva.

O processo de identificação histórica da gênese e desenvolvimento dos direitos e garantias individuais na Constituição brasileira de 1988, partindo da análise dos acontecimentos, processos e instituições que permitem a compreensão da sua natureza, função e a influência existente nos dias de hoje, além da percepção da continuidade e entrelaçamento de fenômenos (LAKATOS; MARCONI, 2017), é de suma importância para verificar a influência das normas de Direito Internacional dos Direitos Humanos na formulação de determinados dispositivos constitucionais.

Nesse sentido, a tensão existente entre o status normativo e a inserção de dispositivos na Constituição pode ser analisada à luz dos debates concretos existentes no momento em que ocorreu a formulação constitucional, para que não somente seja verificada a coerência dos textos, mas também as intenções dos legisladores.

\section{A Construção do Capítulo das Garantias e Direitos Individuais pela Assembleia Nacional}

Constituinte

O processo de eleição dos representantes havia sido conturbado (VIEIRA, 2018), em primeiro momento, foi criado o regimento interno da própria constituinte, o mecanismo debatido para que o processo constitucional fosse instituído. Foi determinada a existência de Oito Comissões temáticas e três Subcomissões para cada Comissão Temática, configurando 
assim 24 Subcomisões encarregadas de tratar de temas específicos, que formaram a estrutura do texto constitucional, na qual se encarregaram de realizar a elaboração dos Títulos, Capítulos, e sistematização dos dispositivos aprovados pelas Comissões, além da elaboração do projeto de Constituição, votação e redação final da matéria - Plenário da Assembleia Nacional Constituinte e Comissão de Redação ${ }^{7}$.

${ }^{7} 1$ - Comissão da soberania e dos direitos e garantias do homem e da mulher subcomissão da nacionalidade, da soberania e das relações internacionais subcomissão dos direitos políticos, dos direitos coletivos e garantias subcomissão dos direitos e garantias individuais. 2 - Comissão da organização do estado subcomissão da união, distrito federal e territórios subcomissão dos estados subcomissão dos municípios e regiões. 3 - Comissão de organização dos poderes e sistema de governo subcomissão do poder legislativo subcomissão do poder executivo

O texto constitucional foi formulado em um momento de intensas reivindicações, que não somente contaram com a intervenção dos legisladores, mas também de amplos setores da sociedade civil, como trabalhadores, categorias econômicas, movimentos sociais (BARROSO, 2014). No momento de aprovação da nova constituinte, Barroso (2014) também afirma que as mudanças ocorrem não somente em âmbito institucional, mas também se modificou o "sentimento constitucional", elevando maior legitimidade aos direitos consolidados na Carta.

A abordagem direcionada aos direitos e garantias individuais ocorre em razão da intensa preocupação internacional em regular tais direitos, seja pela sua natureza de inviolabilidade e pela necessidade de regulação destes direitos devido o contexto de violação ao qual estavam inseridos. Por esta razão, o capítulo que reflete de forma mais específica a salvaguarda destes direitos, é o Capítulo II, que trata dos "Direitos e Deveres Individuais e coletivos inserido no Título dos "Direitos e Garantias Fundamentais", expressamente pelo conteúdo normativo do artigo $5^{\circ}$ da Constituição.

A necessidade de análise das congruências entre o referido dispositivo e as normas internacionais, ensejou a verificação específica constante na Tabela 1. A pesquisa para o artigo foi organizada pela ordem crescente dos incisos constitucionais. O recorte metodológico é motivado também pela pouca alteração em seus dispositivos por meio de emendas, pois levase em consideração a quantidade de emendas constitucionais realizadas neste documento, que comparada com outras em mesmo estágio de desenvolvimento, apresenta um quantitativo maior (MAUES, 2020). Assim, para a construção da presente análise, a Tabela 1 foi construída com o intuito de sistematizar a similaridade entre os artigos presentes na Constituição e os Tratados de Direitos Humanos, conforme expresso a seguir:

Tabela 1 - Exame Comparativo entre os dispositivos Constitucionais e Tratados de Direitos Humanos 


\begin{tabular}{ccc}
\hline Artigo & Assunto/ Texto Constitucional & Norma Internacional Semelhante \\
\hline Art. $5^{\circ}$, Caput & Igualdade e não Discriminação & art. 7 DUDH \\
& & art.26 PIDCP
\end{tabular}

subcomissão do poder judiciário e do ministério público. 4 - Comissão da organização eleitoral, partidária e garantia das instituições subcomissão do sistema eleitoral e partidos políticos subcomissão de defesa do estado, da sociedade e de sua segurança subcomissão de garantia da constituição, reforma e emendas. 5 - Comissão do sistema tributário, orçamento e finanças subcomissão de tributos, participação e distribuição das receitas subcomissão de orçamento e fiscalização financeira subcomissão do sistema financeiro. 6 - Comissão da ordem econômica subcomissão de princípios gerais, intervenção do estado, regime da propriedade do subsolo e da atividade econômica subcomissão da questão urbana e transporte subcomissão da política agrícola e fundiária e da reforma agrária. 7 - Comissão da ordem social subcomissão dos direitos dos trabalhadores e servidores públicos subcomissão da saúde, seguridade e do meio ambiente subcomissão dos negros, populações indígenas, pessoas deficientes e minorias. 8 - Comissão da família, da educação, cultura e esportes, da ciência e tecnologia e da comunicação subcomissão da educação, cultura e esportes subcomissão da ciência e tecnologia e da comunicação subcomissão da família, do menor e do idoso. 9 - Comissão de sistematização. 10 - Comissão de redação.

\begin{tabular}{|c|c|c|}
\hline & & $\begin{array}{l}\text { art. } 24 \mathrm{CADH} \\
\text { art. II DADDH }\end{array}$ \\
\hline Art. $5^{\circ}, \mathrm{I}$ & Igualdade entre Homens e Mulheres & art. 2'C' 15.1 Conv. Mulher ONU \\
\hline \multirow[t]{2}{*}{ Art. $5^{\circ}, \mathrm{III}$} & $\begin{array}{c}\text { Transcriçãa quase integral do texto da } \\
\text { DUDH sobre tortura }\end{array}$ & $\begin{array}{l}\text { art. } 5 \text { DUDH } \\
\text { art. } 7 \text { PIDCP }\end{array}$ \\
\hline & & $\begin{array}{c}\text { art. } 1 \text { Conv. Tortura ONU } \\
\text { art. } 2 \text { Conv. Tortura, art. } 5.2 \\
\text { CADH }\end{array}$ \\
\hline Art. $5^{\circ}, \mathrm{IV}$ & Liberdade de Expressão & $\begin{array}{l}\text { art. 19 DUDH } \\
\text { art.19.2 PIDCP } \\
\text { art.13.1 CADH }\end{array}$ \\
\hline Art. $5^{\circ}, \mathrm{V}$ & Direito de Resposta & art. $14 \mathrm{CADH}$ \\
\hline \multirow[t]{2}{*}{ Art. $5^{\circ}, \mathrm{VI}$} & Liberdade de Religião & art. 18.1 PIDCP \\
\hline & & $\begin{array}{l}\text { art. } 12.1 \mathrm{CADH} \\
\text { art. III DADDH }\end{array}$ \\
\hline \multirow[t]{2}{*}{ Art. $5^{\circ}, \mathrm{IX}$} & Liberdade de Expressão & art. $19 \mathrm{DUDH}$ \\
\hline & & $\begin{array}{l}\text { art. } 13.3 \mathrm{CADH} \\
\text { art. IV DADDH }\end{array}$ \\
\hline \multirow[t]{3}{*}{ Art. $5^{\circ}, \mathrm{X}$} & Direito à Inviolabilidade & art. 12 DUDH \\
\hline & & art. $11.2 \mathrm{CADH}$ \\
\hline & & art. IX DADDH \\
\hline Art. $5^{\circ}$, XIII & Liberdade de Profissão & art. 23.1 DUDH \\
\hline Art. $5^{\circ}, \mathrm{XIV}$ & Liberdade de Acesso à Informação & $\begin{array}{l}\text { art.19.2 PIDCP } \\
\text { art.13 } \mathrm{CADH}\end{array}$ \\
\hline \multirow[t]{4}{*}{ Art. $5^{\circ}, \mathrm{XV}$} & Liberdade de Locomoção & art. 13 DUDH \\
\hline & & art.12.1 e 12.2 PIDCP \\
\hline & & art. $22.1 \mathrm{CADH}$ \\
\hline & & art. VIII DADDH \\
\hline \multirow[t]{3}{*}{ Art. $5^{\circ}, \mathrm{XVII}$} & Liberdade de Associação & art. 23.4 DUDH \\
\hline & & art. 22.2 PIDCP \\
\hline & & $\begin{array}{c}\text { art.16 CADH } \\
\text { art. XXII DADDH }\end{array}$ \\
\hline Art. $5^{\circ}$, XXII & Direito de Propriedade & art. 17 DUDH \\
\hline
\end{tabular}


Art. $5^{\circ}$, XXXIX

Art. $5^{\circ}, \mathrm{XL}$ Art. $5^{\circ}$, XLVII, A), C), E)

Art. $5^{\circ}$, LIII

Art. $5^{\circ}$, LIV

Art. $5^{\circ}, \mathrm{LV}$

Art. $5^{\circ}, \mathrm{LXI}$

Art. $5^{\circ}$, LXIII

Art. $5^{\circ}, \mathrm{LXXV}$

Art. $5^{\circ}$, LXXVIII
Direito à Legalidade

Direito à Não Retroatividade de Lei

Proibição da Pena de: Morte/Cruéis ou

de Trabalhos Forçados

Devido Processo Legal por Autoridade

Competente

Devido Processo Legal

Contraditório e Ampla Defesa

Presunção de Inocência

Contra Prisão Arbitrária

Direito de Defesa

Indenização por Erro Judiciário

Razoável Duração do Processo

Fonte: TEREZO, Cristina; NEGRÃO, Sofia, 2021. art. 11. 2 DUDH

art. 15.1 PIDCP

art. $9 \mathrm{CADH}$

art. 11. 2 DUDH

art. 6.2, PIDCP

art. 4.3

art. 7 PIDCP

art. 6.2 CADH

art. 2.3 'B' PCPP

art 8.1 CADH

art. 11.2 DUDH

art. 8. 2. D CADH

art. 11.2 DUDH

art. 2.3 'B' PIDCP

art. 14.3 'B' PIDCP

art. 8.2 ' $\mathrm{D}$ ' $\mathrm{CADH}$

art. 14.2 PIDCP

art. 8.2 CADH

art. 9 DUDH

art. 8.2 'D' $\mathrm{CADH}$

art. $10 \mathrm{CADH}$

art. 7.5 CADH

Em outro aspecto, para o critério de aproximação e compatibilidade, foi utilizada a verificação por meio das palavras-chave presentes no núcleo de cada artigo, para que fossem encontrados os artigos que mais se assemelhavam em sua escrita literal, aos conceituados no âmbito do Direito Internacional dos Direitos Humanos. Ademais, por serem artigos que foram alvos de reduzidas modificações, são elementos que podem expressar a vontade do legislador constituinte originário em estabelecer direitos e garantias individuais mínimos na Constituição e a prevalência desta intenção no decorrer do tempo, pelo legislador constituinte reformador, que pouco se debruçou sobre a temática.

Esta análise também selecionou apenas os tratados que foram assinados antes da consolidação da Assembleia Nacional Constituinte, com a finalidade de selecionar apenas as normas que, por sua expressão internacional, poderiam influenciar de forma direta ou indireta a escrita do texto constitucional, sendo selecionados os seguintes documentos para a análise: Declaração Universal dos Direitos Humanos, Pacto Internacional dos Direitos Civis e Políticos, 1966 (PIDCP); Convenção sobre Eliminação de Todas as Formas de Discriminação Racial, 1966; Convenção sobre Eliminação de Todas as Formas de Discriminação contra a Mulher, 1979; Convenção das Nações Unidas contra a Tortura, 1894; e no âmbito da Organização dos 
Estados Americanos: Declaração Americana dos Direitos e Deveres do Homem, 1948 (DADDH); Convenção Americana sobre Direitos Humanos, 1969; Convenção Americana para Prevenir e Punir a Tortura, 1985.

A abrangência de temáticas do conjunto em análise permitiu uma pesquisa ampla sobre a congruência destes artigos com normas internacionais. Ao todo, foram encontrados 25 incisos (incluído o caput do artigo), que continham similaridades específicas, na sua forma escrita e objetivo principal. Dentre estes, as maiores similaridades foram encontradas com a Declaração Americana dos Direitos e Deveres do Homem (1948), Declaração Universal dos Direitos Humanos (1948) e Pacto Internacional dos Direitos Civis e Políticos (1966). O primeiro documento, quando comparado ao texto constitucional, apresentou dispositivos que se assemelharam a transcrições. Os demais, demonstraram núcleos com palavras semelhantes.

Da interação específica realizada durante a comparação preliminar, foi possível compreender que a semelhança nos textos pode ter sido resultado da direta intenção do legislador constituinte, não somente com o compromisso em proteger e garantir direitos humanos à luz das confluências internacionais, mas também do manejo dos textos de tratados internacionais e declarações, ainda que o país não houvesse ratificado e depositado os documentos. Desta maneira, evidencia-se a necessidade de compreender o conteúdo dos debates realizados para a formulação do texto constitucional, durante a Assembleia Constituinte, com o intuito de compreender as reais aproximações promovidas no momento.

a. As Atas da Assembleia Nacional Constituinte e a Interação dos Legisladores com as normas do Direito Internacional dos Direitos Humanos

Com base no recorte metodológico utilizado e para maior compreensão e delimitação metodológica, foi realizada uma análise específica dos debates realizados na Assembleia Nacional Constituinte. Nas sessões, primeiramente os assuntos eram levados a cada subcomissão e debatidos, para que, então, fossem levados à apreciação das Comissões e, por esta razão e pelos limites práticos estabelecidos neste trabalho, foram selecionadas as seguintes comissões: Comissão da Soberania e dos Direitos e Garantias do Homem e da Mulher e a Subcomissão dos Direitos e Garantias Individuais, pois estes fomentaram a escrita do Capítulo objeto deste artigo.

Assim, para a verificação proposta, foram utilizadas as Atas da Assembleia Nacional 
Constituinte, em seu conteúdo por ser um conjunto de documentos capaz de sistematizar todos os debates realizados pela matéria, bem como os discursos dos constituintes e dos especialistas convidados para o debate sobre a construção e sentido de determinados dispositivos.

Neste momento, a pesquisa foi realizada por meio primariamente da leitura ampla e geral da ata para a verificação de premissas gerais e identificação de palavras-chave de pesquisa, e, em segundo lugar, pela busca das palavras elegidas. Da eleição, ficaram determinadas as pesquisas pelos nomes de Tratados e Declarações em análise, bem como pelos indicadores "Carta da ONU”, "Direito Internacional”, "Convenção", "direitos humanos”, "Nações Unidas". Ademais, também foram analisados os contextos de fala em cada discurso onde a palavra-chave foi encontrada, para que fosse possível verificar a referência a outros documentos. As análises preliminares sobre as atas foram sistematizadas pesquisas na mesma ordem dos incisos organizados na Tabela 1.

Em primeiro momento, ressalta-se a preferência por especialistas no ramo do Direito Internacional dos Direitos Humanos, a exemplo de Cançado Trindade, que como especialista na área dos direitos humanos e Direito Internacional, apresentou em sessões na Assembleia, questões específicas sobre o funcionamento e consagração de direitos humanos no âmbito dos Sistemas Internacionais de Proteção. No ato de condensar as experiências sobre o assunto, além de delimitar o processo de formulação dos direitos humanos, ele recomendou a utilização dos tratados internacionais, a exemplo da Convenção Americana, como instrumento para a formulação dos $\operatorname{artigos}^{8}$, esta última, com maior amplitude de direitos, sobretudo em razão da instabilidade política do continente, fator que determina a necessidade de configuração de salvaguarda de um mínimo de direitos humanos por meio de normas internas, deveriam ser harmonizadas com o ordenamento jurídico interno a priori ou a posteriori da Constituição.

Em seguida, um dos dispositivos de maior debate na sessão da ANC foi o que tratava sobre o contexto e tipificação da proibição da tortura no texto constitucional; foram travados embates em razão da dimensão da tortura como crime político e como crime comum. Esta tensão entre a elaboração das normas e os direitos humanos que tratavam sobre o assunto, ocorreu em razão da transição democrática e a necessidade de proibição de crimes de "lesa humanidade" cometidos em regime anterior.

A elaboração do texto do art. $5^{\circ}$, inciso III, perpassou por diversas adições ao seu entendimento, sendo declarada a tortura como crime comum, inafiançável, imprescritível e insuscetível de graça ou anistia. Durante os debates, leituras amplas foram realizadas do texto 
da Declaração Universal dos Direitos Humanos, sobretudo em trechos que tratavam expressamente da tortura. Aqui, consolidou-se o debate sobre a inclusão ou não de punições, na qual o Constituinte Joaquim Haickel, abordou que as leis ordinárias devem ser refeitas para obter tratamento constitucional ${ }^{9}$.

No decorrer das Reuniões, os demais especialistas sobre a temática também trataram da necessidade de observação expressa dos tratados internacionais. Antônio Mariz determina a leitura integral do texto da resolução da Assembleia da ONU, que define a tortura. Tais

\footnotetext{
8 "No entanto, há um núcleo mínimo de direitos, tanto no plano global como no regional, proclamados por esses instrumentos internacionais obrigatórios como inderrogáveis. No que se refere ao Pacto das Nações Unidas, menciona-se o direito à vida, a não ser submetido a torturas, ou a penas, ou tratos cruéis, a não ser submetidos a escravidão ou servidão, a não ser encarcerado por não cumprimento de obrigação contratual, a não ser condenado por aplicação retroativa do Direito Penal, ao reconhecimento da personalidade jurídica e à liberdade de pensamento, consciência e religião. Esse é o Pacto dos Direitos Civis e Políticos das Nações Unidas. A Convenção Europeia coincide com o Pacto dos Direitos Civis e Políticos, grosso modo. ao considerar esses mesmos direitos como inderrogáveis. A Convenção americana - que nos interessa mais de perto - estabelece a inadmissibilidade de suspensão de garantias em relação aos seguintes direitos: direito ao reconhecimento da personalidade jurídica, à vida, e à integridade pessoal, a não ser submetido a escravidão ou servidão, a não ser condenado por aplicação retroativa das penas, à liberdade de consciência e religião, à proteção da família, ao nome, aos direitos da Criança, à nacionalidade e aos direitos políticos (CANÇADO TRINDADE, 1987)".

${ }^{9}$ O Sr. CONSTITUINTE JOAQUIM HAICKEL: - Também acho que pode. Considero o parecer da Constituinte Lúcia Vânia perfeito, bem como a sugestão do Constituinte Jamil Haddad. Apenas acho que na Constituição devemos ter teses e não aprofundamentos. Caso contrário, faremos uma colcha de retalhos. Acho que o substantivo é mais importante nesta Constituição. Creio que a proposta do parecer deve ser incluída na lei ordinária, no Código Penal, mas ultimamente as nossas leis ordinárias têm sido muito ordinárias. Acho que as nossas leis ordinárias devem ter um tratamento Constitucional. Devemos trazê-las para cá, a fim de refazê-las, todas. Acho que esta proposta deve ser encaminhada (BRASIL, 1987).
}

elementos foram incorporados com base na leitura realizada dos instrumentos de Direito Internacional.

Em momento posterior, menção expressa à Declaração Americana dos Direitos e Deveres do Homem ocorre quando são travados debates sobre a pena de morte e suas consequências práticas constitucionais. $\mathrm{O}$ caráter irreversível da pena de morte e altamente violador das normas de direitos humanos é considerado em instância máxima ao se analisar a necessidade de manter a norma proibitiva no texto constitucional. Ademais, em diversos momentos do debate constituinte, o texto da Declaração Universal dos Direitos Humanos é citado como barreira "protetiva ao criminoso", quando se referiam à proibição da pena de morte em âmbito internacional. Assim, a inviolabilidade do direito à vida, protegida no âmbito do Direito Internacional dos Direitos Humanos, foi um dos argumentos propulsores de debates e da proibição da pena de morte.

Ademais, quando se trata sobre a liberdade sindical e seus desdobramentos 
associativos, não foram citados os documentos acima descritos, mas sim a Convenção $\mathrm{n}^{\circ} 87$ da Organização Internacional do Trabalho, que tratava sobre questões trabalhistas. Não obstante, não dispor de forma expressa sobre direitos humanos, resta evidente que fontes internacionais foram utilizadas para a construção de direitos sindicais existentes na Constituição.

Os constituintes também consideram elementos essenciais para a construção de uma sociedade democrática e, por meio da inserção de direitos fundamentais, são protegidas as bases democráticas. A construção do texto que fala sobre igualdade e não discriminação, mais precisamente o caput do artigo ora em análise, já havia sido objeto de construção e, se tornou de abrangência unânime na ANC de 1987.

Há também que se considerar na pesquisa, a presença de elementos que já constavam na redação da constituinte anterior de 1967, mas que na Assembleia Nacional Constituinte ganharam nova redação ou alguns elementos foram modificados como, por exemplo, a condição de igualdade perante à $l \mathrm{ei}^{10}$, os direitos de liberdade religiosa ${ }^{11}$, liberdade de expressão ${ }^{12}$, pessoalidade da pena ${ }^{13}$ e ampla defesa.

Tais direitos foram restringidos por meio dos atos institucionais durante a ditadura militar ou, foram transgredidos de forma arbitrária no mesmo período. Por esta razão, a preocupação no debate sobre a proteção de direitos e garantias capazes de proteger a integridade pessoal, foram consideradas no período da elaboração.

\section{Considerações Finais}

As escolhas dos legisladores em adicionar direitos e garantias individuais e fundamentais revelam a preocupação do legislador originário em promover direitos em sede hierarquicamente superior às outras normas do ordenamento, para que estes não sejam transgredidos por outros motivos. O processo de transição democrática trouxe inúmeros debates acerca de crimes contra a humanidade cometidos durante a ditadura militar, que, aliado à movimentação internacional para a criação de instrumentos capazes de coibir outros acontecimentos desta natureza, bem como com o contexto latinoamericano de redemocratização e intensificação de interações das constituintes com a progressiva proteção de direitos humanos, foram elementos que influenciaram diretamente a composição da Carta.

Este contexto pode ser também um dos principais motivos para a amplitude dos debates sobre o conceito de tortura na Comissão de Direitos e Garantias Individuais, na qual 
foram lidos diversos textos internacionais e foi discutida a função de órgãos responsáveis pelo monitoramento ou adesão de tratados de direitos humanos. Assim, normas que revelavam a primazia pela proteção da integridade da pessoa cidadão brasileira e também estrangeira detiveram considerações amplas dos legisladores.

\footnotetext{
10 “Art 150 - A Constituição assegura aos brasileiros e aos estrangeiros residentes no Pais a inviolabilidade dos direitos concernentes à vida, à liberdade, à segurança e à propriedade, nos termos seguintes:

$\S 1^{\circ}$ - Todos são iguais perante a lei, sem distinção, de sexo, raça, trabalho, credo religioso e convicções políticas. O preconceito de raça será punido pela lei.” (BRASIL, 1967)

${ }_{11} 6^{\circ}$ - Por motivo de crença religiosa, ou de convicção filosófica ou política, ninguém será privado de qualquer dos seus direitos, salvo se a invocar para eximir-se de obrigação legal imposta a todos, caso em que a lei poderá determinar a perda dos direitos incompatíveis com a escusa de consciência.(BRASIL, 1967)

${ }^{12} \S 8^{\circ}$ - É livre a manifestação de pensamento, de convicção política ou filosófica e a prestação de informação sem sujeição à censura, salvo quanto a espetáculos de diversões públicas, respondendo cada um, nos termos da lei, pelos abusos que cometer. É assegurado o direito de resposta. A publicação de livros, jornais e periódicos independe de licença da autoridade. Não será, porém, tolerada a propaganda de guerra, de subversão da ordem ou de preconceitos de raça ou de classe. (BRASIL, 1967).

${ }^{13} \S 13$ - Nenhuma pena passará da pessoa do delinqüente. A lei regulará a individualização da pena.(BRASIL, 1967).
}

Pelo mesmo motivo, a pena de morte também foi elemento com enormes debates na ANC, com um total de 463 menções a esta punição, evidenciou-se a tensão existente entre as normas protetivas de direitos humanos, os constituintes que apoiavam sua inserção efetiva em texto constitucional e os demais que consideraram a proteção humanitária, como uma limitação à esfera punitiva do Estado. Ademais, a oposição contra a tortura e demais penas ou tratamentos desumanos ou degradantes, também foi alvo de destaque pelos constituintes, sobretudo em razão dos acontecimentos recentes que antecediam a Assembleia Nacional Constituinte.

Outro aspecto importante é que não foram considerados artigos que já sofreram a incidência de emendas, tendo em vista que o legislador constituinte derivado já se debruçou sobre a incidência de outras normativas internacionais já ratificadas pelo Brasil e algumas normas de direitos humanos já possuíam status hierárquico superior aos demais tratados.

Em uma das limitações metodológicas, não foram analisadas constituições anteriores que já possuíam textos semelhantes aos oriundos de normas internacionais; a presente delimitação temática considerou não somente os textos, mas também os debates que incidiam na proteção destes direitos de forma ampla, com o intuito de compreender as intenções do legislador constituinte originário na materialização dos direitos em acordo com as interpretações admitidas pelas fontes de Direito Internacional, por meio de instituições democráticas que envolviam a assunção de responsabilidades políticas de Estado. 
Portanto, a Assembleia Nacional Constituinte, por meio das Comissões ora relacionadas, apresentou uma ampla gama de direitos individuais a serem protegidos e, destes, sobretudo os crimes de lesa-humanidade considerados internacionalmente foram debatidos para que não somente fossem positivados em texto constitucional, mas sua interpretação possuísse sentido semelhante ao relacionado nas sessões. Ademais, a presença de especialistas, a exemplo de Cançado Trindade, fomentou debates de cunho específico para o entendimento dos posicionamentos das Cortes Internacionais e direitos evidenciados em tratados.

\section{REFERÊNCIAS}

ANAYA MUÑOZ, Alejandro. Regimes internacionais de direitos humanos. Revista Internacional de Direitos Humanos. SUR. v.14, n. 25, São Paulo, 2017, p. 171-188. Disponível em: http://sur.conectas.org/wp-content/uploads/2017/09/sur-25-portuguesalejandro-anaya-munoz.pdf. Acesso em: 24 de out. de 2021.

BARBOSA, Leonardo Augusto de Andrade. História constitucional brasileira: mudança constitucional, autoritarismo e democracia no Brasil pós-1964. Brasília: Câmara dos Deputados, 2012.

BARROSO, Luís Roberto. O constitucionalismo democrático no Brasil: crônica de um sucesso imprevisto. In: GUERRA, Roberta Freitas; SILVA, Fernando Laércio Alves da. NERO, Patrícia Aurélia del. (Coord.). Neoconstitucionalismo em perspectiva. Viçosa: UFV, 2014, p. 27-61

BRASIL. Senado Federal. Atas da Assembleia Nacional Constituinte. Subcomissão dos Direitos e Garantias Individuais. https://www.senado.leg.br/publicacoes/anais/constituinte/ComESub.pdf. Acesso em: $01 \mathrm{de}$ jul. de 2021.

BRASIL. Senado Federal. Atas da Assembleia Nacional Constituinte. Comissão dos Direitos e Garantias do Homem e da Mulher.

https://www.senado.leg.br/publicacoes/anais/constituinte/ComESub.pdf. Acesso em: $01 \mathrm{de}$ jul. de 2021.

BRASIL. Senado Federal. Câmara dos Deputados. Processo Constituinte (documentos). Publicação eletrônica. Brasília, 2013b. Disponível em:

http://www2.camara.leg.br/atividadelegislativa/legislacao/Constituicoes_Brasileiras/constituic ao-cidada/o-processoconstituinte. Acesso em: 10 de jul. 2021.

CANÇADO TRINDADE, Antônio Augusto. Desafios e conquistas do Direito Internacional dos Direitos Humanos no início do século XXI. 2006. v. 20, p. 20. Disponível em: https://www. oas. org/dil/esp/407-490\% 20cancado\% 20trindade\% 20OEA\% 20CJI. Acesso em: 20 nov. 2020. 
GARGARELLA, Roberto. Sobre el "Nuevo Constitucionalimo Latinoamericano. Rev. Urug. Cienc. Polít., Montevideo, v. 27, n. 1, p. 109-129, jun. 2018.

GIL, Antônio Carlos. Métodos e técnicas de pesquisa social. 6. ed. São Paulo: Atlas, 2019.

LAKATOS, Eva Maria; MARCONI, Marina. Fundamentos de metodologia científica. 8. ed. São Paulo: Atlas, 2017.

MAUÉS, Antonio Moreira. 30 anos de Constituição, 30 anos de reforma constitucional. Revista Direito GV, v. 16, p. 1-30, 2020.

MAUÉS, Antonio Gomes Moreira; MAGALHÃES, Breno Baía. A Recepção dos Tratados de Direitos Humanos pelos Tribunais Nacionais: Sentenças Paradigmáticas de Colômbia, Argentina e Brasil. Revista Direito, Estado e Sociedade, n. 48, 2016.

NOBRE, Marcos. Imobilismo em movimento: Da redemocratização ao governo Dilma. São Paulo: Companhia das Letras, 2013.

QUIVY, Raymond; CAMPENHOUDT, Luc Van. Manual de Investigação em Ciências Sociais. Lisboa: Gradiva, 1992.

VIEIRA, Oscar Vilhena. A Batalha dos Poderes. São Paulo: Companhia das Letras, 2018. 